\title{
Somewhere Out There May Be That Life-Saving Research
}

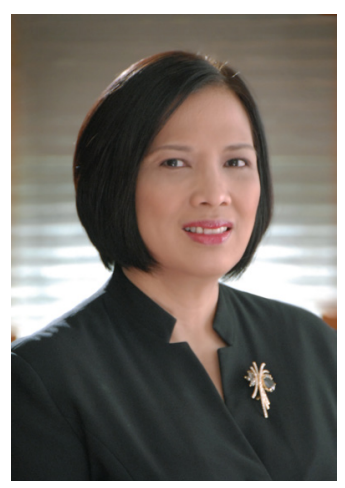

We are happy to report that JAFES, after being listed in the Directory of Open Access Journals (DOAJ), is now included in the Research 4 Life (R4L) of the Health InterNetwork Access to Research Initiative (HINARI), a program under the World Health Organization. HINARI provides free or very low cost online access to biomedical/social science journals to benefit notfor-profit institutions in developing countries.

JAFES is now among the publishers providing free access to its articles to those who have limited financial capability. We believe that the benefits of scientific knowledge should be for everyone, free to build upon, readily available to generate further understanding of endocrine and metabolic conditions that are steadily increasing in prevalence worldwide.

We also believe in learning from one another: in this issue, we have once more featured summary articles of country specific clinical practice guidelines, this time on dyslipidemia. This is one way of stimulating discussion and reflection on locally relevant patient care.

We have also opened our doors once more as a platform for featuring abstracts of the oral and poster presentations in the recently concluded Asia-Oceania Congress of Endocrinology (AOCE) held in Cebu City, Philippines. Through this, we may have a glimpse of the current scientific and research directions occurring in the region. We hope the authors will proceed to writing up their full manuscripts and consider JAFES as their journal of choice.

It is the objective of JAFES to ensure that quality endocrine research written by members of the AFES and colleagues from other countries are appropriately processed, made available to all and protected from the vulnerabilities inherent to the internet.

Last issue, we announced that we have overhauled our official website. We have had three months of experience since the migration to Open Journal Systems (OJS), our new open source online editorial management system. Do bear with us in this period of transition: it is a learning process for us, as much as our reviewers and authors are also getting accustomed to the electronic system. OJS does provide a lot of benefits in managing our manuscripts from submission to publication and we did receive quite a number of submissions through this platform. We look forward to better efficiency, better services, and quality improvements over time.

An integral part of JAFES' obligation to our valuable authors is ensuring that their articles are searchable and --- in the parlance of the world wide web --- protected from "link rot," weak and broken links leading to nowhere or to the wrong content. JAFES fulfills this commitment through our partnership with CrossRef. Now, all articles from the $26^{\text {th }}$ volume to present have unique Digital Object Identifiers (DOIs). These DOIs will ensure link permanence, aside from improving searchability of our articles and driving content to our website.

Beyond the quest for improved visibility and online presence; beyond indexing, impact factors and other journal metrics; beyond academic pressures and requirements for scientific output, there is that hope that somewhere, out there, may be that life-saving research. This can be achieved only if we as a journal are truly and unequivocally open access. In this respect, we hope to fulfil yet one more noble objective: to be a catalyst for further knowledge - without the limitation of the ability to pay for the right to have a voice and to fully view manuscripts.

For the patients that we serve in the region, this is what matters most, at the end of the day.

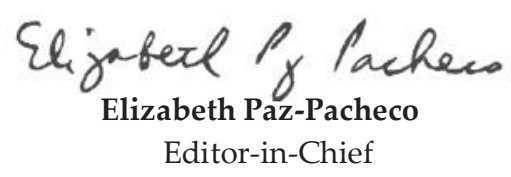

http://dx.doi.org/10.15605/jafes.029.02.01 